\title{
NOTAS SOBRE A VIOLÊNCIA DO ESTADO CONTRA OS MOVIMENTOS DE TRABALHADORES RURAIS
}

\section{NOTES ABOUT STATE VIOLENCE AGAINST WORKERS MOVEMENTS RURAL}

\author{
Gustavo de Souza Preussler ${ }^{1}$
}

\section{RESUMO}

O presente artigo faz um estudo sobre a violência estrutural do Estado e o poder econômico enquanto instrumentos de opressão e propulsor dos conflitos agrários. O objetivo geral é esclarecer no que consiste violência estrutural no Brasil contemporâneo e suas implicações nos conflitos agrários. Como objetivos específicos, pretende delinear a atuação de instrumentos econômicos de opressão, expor a divisão de classes no âmbito rural, a violência econômica e seus reflexos na violência institucional (atuação da Justiça de Classe).

Palavras-chave: Violência estrutural, Movimentos sociais, Criminologia

\begin{abstract}
The presente article make a study about the structural violence of State and the economic power while instruments of oppression and propellant of land conflicts. The general objective is make clear on what consists structural violence on contemporary Brazil and its implications on land conflicts. As specifics objectives, aims to outline the performance of economics instrument of oppression, expose the class division on rural areas, the economic violence and its reflex in institucional violence (performance of Class Justice).
\end{abstract}

Keywords: Structural violence, Social movements, Criminology

\footnotetext{
${ }^{1}$ Doutorado em Direito pela Universidade do Estado do Rio de Janeiro - UERJ, Rio de Janeiro, (Brasil). Professor associado pela Universidade Federal da Grande Dourados - UFGD, Mato Grosso do Sul, (Brasil). E-mail: guspreussler@hotmail.com
} 


\section{INTRODUÇÃO}

Toda violência proveniente do Estado contra o sujeito é uma violência política. Toda pessoa rotulada como criminoso é um criminoso político em termos genéricos (BATISTA, 2003). O crime não é: ele torna-se (CHRISTIE, 2011, pp. 15-16). O criminoso não existe, ele é selecionado.

Max Weber, um dos pais da sociologia e teórico da economia política, definiu que o Estado possui o monopólio da violência legítima. Violência esta que somente pode ser exercida por comunidades plenamente desenvolvidas. A violência é exercida por aparatos em um verdadeiro sistema penal ativo responsável pelo direito vivo, ou sistema penal dinâmico.

Acreditar no conceito de violência legítima e desconsiderar todo e qualquer terrorismo penal institucionalizado e imposto pelo sistema capitalista é uma forma ingênua de considerar que existe igualdade material em nossa sociedade. A legitimação da violência perde força e sentido a partir do momento em que os movimentos sociais começam a reivindicar direitos em uma atitude democrática e emancipatória (SOUSA SANTOS, 2007). No entanto, o Estado tem apresentado uma postura de repressão à conduta emancipatória e reivindicatória desses movimentos sociais. Como alegoria, vejamos uma versão do mito de Prometeu, considerado o primeiro rebelde:

A violência na relação entre o Estado e os movimentos sociais pode ser definida como a violência institucional (legítima ou do Estado) e a violência anti-institucional (ilegítima ou não pertencente ao Estado). A lógica dos massacres e a chave da impunidade pertencem em parte aos próprios conceitos abstratos.

Os protestos sociais se apresentam no senso comum criminológico como atos de sedição. No entanto, trata-se de uma forma de violência que pretende romper com a violência sistêmica dita legítima do Estado. A ruptura entre legítimo ou ilegítimo em termos de violência é tão clara nas democracias latinoamericanas que o direito penal brasileiro tipificou o crime de autotutela de direito, em que protestos sociais e atividades de movimentos sociais sem terras foram considerados como atos de subversão de violação da soberania. 


\section{DIALÉTICA ENTRE VIOLÊNCIA INSTITUCIONAL E VIOLÊNCIA ANTI- INSTITUCIONAL}

Os conflitos violentos - dialética entre a violência institucional e a anti-institucional - sempre estiveram presentes na história.

A sociedade brasileira é pautada no capitalismo tardio, tendo sempre sido dependente - como todo país periférico - do centro, representada pelas instituições de dominação econômica globais, ou a santa trindade do capitalismo de barbárie: o Fundo Monetário Internacional (FMI), o Banco Mundial (BM) e a Organização Mundial do Comércio (OMC). Todos fazem parte desse grande moinho de gastar gente.

O capitalismo brasileiro tem sua matriz em uma economia de exportação agrária pautada no trabalho escravo. Após a abolição da escravatura em 1888, o modelo agrário manteve-se em coexistência com o sistema de trabalho industrial.

Enquanto as oligarquias se formavam tardiamente na industrialização no Sul e Sudeste, as regiões Norte, Nordeste e Centro-Oeste "permaneceram em posição política e econômica subordinada, pela predominância da produção agropecuária, o que equivale a afirmar a subordinação de produção agrária à indústria” (SANTOS, 1984, p. 76).

A transformação da estrutura econômica do Brasil de agrícola escravista para industrial com base na exploração da mão de obra assalariada pode ter influenciado a modificação da estrutura de classes. No entanto, alguns traços podem ser vislumbrados como permanências históricas: a) o trabalho escravo é proibido por lei, na estrutura subjacente do Estado capitalista; entretanto, essa mão de obra é utilizada; e b) há grande polarização da riqueza e da propriedade de terras no Brasil.

A concentração da propriedade fundiária se dá em razão da entrada do capital estrangeiro no Brasil e pelo regime militar, cujas diretrizes de cunho político e econômico colocam o país em uma situação de subordinação ao imperialismo. Isso faz com que a concentração da propriedade fundiária se polarize em prol de grandes corporações (SANTOS, p. 77). 
A grande burguesia industrial-financeira e imperialista - segundo Juarez Cirino dos Santos - "se afirma como fração hegemônica do bloco histórico, mantendo sob controle direto o aparelho de Estado e a política de exploração econômica da força de trabalho e dos recursos naturais brasileiros" (SANTOS, 1984, p. 79).

No contexto das estruturas de classes no Brasil, pode-se afirmar que o capitalismo brasileiro é monopolista. Esse monopólio domina também os "sistemas e aparelhos internos de organização, controle e disciplina das relações sociais” (MENEGAT, 2012, p. 33). Em linhas gerais, o mesmo grupo - pequeno grupo - ou corporações que têm o poder econômico possuem o poder político, coordenando e determinando a criminalização secundária.

Como dito anteriormente, podemos dividir a estrutura de classes em dois polos ou grandes blocos: dominadores/criminalizadores e dominados/criminalizados.

No bloco dominante, aparecem os latifundiários, grandes proprietários de terras ou grandes corporações que contribuem para a reprodução da miséria absoluta na grande massa do proletariado rural. Este ator possui o poder político e econômico de grande escala e é capaz de produzir e construir um sistema penal subterrâneo.

O bloco dominado é constituído pelos seguintes integrantes:

a) Pequena burguesia proprietária (exploração de reduzido número de empregados);

b) Camponeses pobres (com e sem terra: proprietários minifundistas, posseiros, parceiros e arrendatários);

c) Semiproletariado rural (parceiros e meeiros que vendem, temporariamente, sua força de trabalho, em transição para a classe rural fundamental);

d) Proletariado rural, como classe rural fundamental, compreendendo os assalariados agrícolas permanentes);

e) Subproletariado rural: boias-frias (com trabalho eventual em algumas épocas do ano de maior atividade agrícola) (SANTOS, 1983, p. 83).

Esse conflito entre classes é o que se pode chamar de revolução social, ou, segundo Boaventura de Sousa Santos, uma contra-hegemonia que tem como principal objetivo reinventar a democracia e, por sua vez, o direito mediado pelos novos movimentos sociais, tal como é o Movimento dos Trabalhadores Rurais Sem Terra. Segundo o sociólogo português, “o campo jurídico de disputa em torno dos conflitos estruturais é altamente demarcado. A luta 
contra-hegemônica encontra limites e reações contrárias, algumas extremamente influentes e poderosas, tanto maiores quanto mais os conflitos incidirem sobre objetos de elevada disputa entre diferentes interesses [...]" (SOUSA SANTOS, 2011, p. 101).

Essa perspectiva acaba gerando um risco para a ordem estabelecida da classe hegemônica, o que faz a mesma utilizar-se de todo o aparelho organizado de poder para fins ilícitos. Assim, no plano prático, a violência estrutural no Brasil e nos aparelhos de Estado cria um processo de criminalização secundária hegemônica.

\section{SOBRE A FORMA DE VIOLÊNCIA PRODUZIDA PELO SISTEMA DE JUSTIÇA PENAL HEGEMÔNICO}

A produção e reprodução da violência se dividem em duas grandes formas: a violência estrutural e a violência institucional. A primeira reporta-se à relação de produção e de trabalho, enquanto a segunda está ligada ao funcionamento das estruturas de poder de Estado, ou seja, dos aparelhos ideológicos e repressivos do Estado. No entanto, no âmbito penal, não há como se cindir analiticamente as formas de violência. Isso porque toda a forma de violência institucional - produzida pelo sistema de justiça penal e de seus aparelhos repressivos - são reproduções do sistema de violência estrutural, próprio do sistema econômico.

Se verificarmos a construção histórica da maioria dos litígios penais, em que o Estado e suas estruturas de opressão são autores de delitos, notaremos que ela acaba expressando a concepção econômica e o modo de produção capitalista. A economia da pena é a mesma economia da opressão penal, seja excluindo os miseráveis, seja distribuindo imunidades a quem tem poder econômico (CHAPMAN, 1968). Rusche e Kirchheimer sintetizam essa ideia afirmando que "todo sistema de produção tende a descobrir formas punitivas que correspondem às suas relações de produção" $(2004$, p. 20).

No Brasil, bem como nos demais países de capitalismo tardio - de opressão videofinanceira -, a violência estrutural está presente na estrutura de classes sociais, pela qual o bloco dominado está oprimido pelo bloco dominante. Assim, “a violência estrutural compreende toda violência ligada às relações de produção dominantes [...]” (SANTOS, 1984, 
p. 86). No contexto das relações de produção rural, a que se vinculam os massacres no campo, a lógica de neocolonização do território agrícola expressa uma violência estrutural e esta também encontra provas dentro das políticas da Santa Trindade Neoliberal já apontada acima (Fundo Monetário Internacional, Banco Mundial e Organização Mundial do Comércio). Essas instituições internacionais geralmente acusam o Estado de Direito como a razão pela qual os países ricos não fazem investimentos em países mais pobres. O Estado de Direito seria uma espinha dorsal, essencial para o desenvolvimento da economia de mercado, onde as leis e a aplicabilidade do direito seguem regras rígidas e previsíveis. Trata-se de um neocolonialismo, também denominado de boa governança. São na verdade "receitas normativas para a liberalização do mercado e a abertura dos mercados locais aos investimentos estrangeiros (o que em geral prepara o caminho para a pilhagem)", que "chegam em um pacote embrulhado pela respeitabilidade do Estado de Direito" (MATTEI; NADER, 2013, p. 22-23).

No Brasil, o Banco Mundial criou três programas de lógica capitalista para aquisição de terras: Cédula da Terra, Banco da Terra e Crédito Fundiário de Combate à Pobreza. A princípio e a grosso modo, dá-se a impressão de que esses programas são relevantes e ajudam as pessoas a deixar a situação de explorados e libertarem-se da opressão.

A Cédula de Crédito trata-se de uma política de eliminação do Estado de Bem-Estar Social nos assentamentos, para incluir o acesso à terra via operação bancária de financiamento, ou seja, para compra e venda de terras. Geralmente, essas terras eram de péssima qualidade e com valor superfaturado. Gera-se, assim, um efeito contrário ao supostamente pretendido, ou seja, ao invés de dar instrumentos para que os adquirentes alcançassem a sustentabilidade econômica, na verdade, os mesmos tornaram-se mais miseráveis, uma vez que nunca conseguiam pagar seus financiamentos.

O Banco da Terra tinha como finalidade financiar a aquisição de propriedades e infraestruturas básicas para trabalhadores sem terra ou que possuíam terras insuficientes para a subsistência. A problemática era que, como instituição financeira, além de buscar o lucro através da produção e reprodução da mais-valia absoluta, o Banco da Terra desconsiderava o realismo marginal que o campo proporciona aos pequenos produtores rurais. Por haver críticas severas a essa instituição financeira, cria-se no ano 2000, o projeto de Crédito Fundiário de Combate à Pobreza Rural, preservando, contudo, a integralidade da Cédula de Crédito Rural. 
Essas estratégias acima apontadas demonstram o agravamento da situação da distribuição de terras e a conversão do acesso a estas na forma da lógica de mercado de especulação.

O Brasil possui um dos maiores índices de concentração de terras do planeta. Segundo Maria Orlanda Pinassi, em sua obra Da Miséria Ideológica à Crise do Capital, se levarmos em consideração 35.083 propriedades, ou seja, $1 \%$ do total dos imóveis cadastrados, os latifúndios ocupam 153 milhões de hectares. Isto equivale a quase todo um país do tamanho do Irã. No Brasil, país da exclusão e polarização da propriedade rural, são cultivadas somente $14 \%$ da área passível de plantio e outros $48 \%$ são destinados à pecuária. Fica evidente a ociosidade de terras. Em 1997, dados foram coletados que mostram cifras mais nefastas ainda: 4,5 milhões de agricultores familiares são donos de apenas $25 \%$ das terras passíveis de agricultura, e garantem o sustento de 18 milhões de pessoas, ou seja, $12 \%$ da população (PINASSI, 2009, p. 63). De outro lado, os latifundiários nada contribuem para a alimentação dos brasileiros e tão-somente produzem e reproduzem exclusão social.

Apesar de o critério da espacialização ser amplo, a produção está em relação inversa, ou seja, não passam essas grandes propriedades de sitiocas em uma imensidão de terras, recorrendo o grande proprietário, nas raras vezes, ao arrendamento e à parceria, que na verdade são formas de obtenção de mais-valia-absoluta, sem emprego de força laboral própria. A lógica da exploração e dominação do território pelo arrendamento tem uma origem histórica na formação do Movimento dos Trabalhadores Rurais Sem Terra, muito presente nas Ligas Camponesas, em que eram cobrados valores exorbitantes para a exploração da terra que abrigava antigos engenhos, tais como o Engenho da Galileia. Tratam-se, tanto o arrendamento como a parceria, segundo Franciele Silva Cardoso, de um "contrato que se estabelece entre os proprietários de terra e os camponeses para, diante da dificuldade daqueles - ou desinteresse puro e simples -, empreender e explorar economicamente suas terras" (CARDOSO, 2013, p. 48).

Em comparação, verifica-se que há congruência entre os índices de maior exclusão social ao acesso a terra ou desigualdade da distribuição agrária e a violência contra trabalhadores rurais. Fica claro que a violência estrutural é fator preponderante para a consolidação da violência institucional. No Estado do Pará, por exemplo, onde há maior 
concentração de terras, coexiste maior concentração de violência, ordens judiciais de despejos e reintegração de posse (GIRARDI, 2008, p. 296).

Nota-se, assim, que existe uma relação entre a polarização da riqueza e a violência no campo. Logo, onde há maior concentração das riquezas na mão de poucos (criminalizadores), há maior distribuição da violência contra muitos (criminalizados). Segundo Manuel Domingos Neto:

Refletindo a gravidade da concentração fundiária no Brasil e o vigor do movimento pela democratização da propriedade da terra, ampliaram-se os conflitos agrários. Segundo a Comissão Pastoral da Terra (CPT), entre 1992 e 1994 a média anual era de 367 ocorrências, envolvendo 214.653 pessoas. Entre 1995 e 1999, a média aumentou: verificaram-se 667 conflitos com 508.507 pessoas envolvidas. Apesar disso, houve uma redução de 5\% da média anual de assassinatos relacionados às lutas por terra no governo de Fernando Henrique Cardoso. Isso não indica necessariamente o abrandamento da repressão, mas possivelmente uma tendência de mudança nos procedimentos coercitivos. O Movimento dos Trabalhadores Rurais Sem Terra (MST) considera que no ano de 2000, cresceram os despejos, as prisões ilegais e os processos judiciais forjados. Isso sugere que os grandes proprietários, sem abandonar a violência privada, recorrem mais à intervenção formal do Estado. Em 2000, entre os catorze trabalhadores assassinados, onze eram militantes do MST. (DOMINGOS NETO, 2004, p. 28).

Dentro da violência estrutural, podemos apontar duas grandes modalidades de manifestação: a primeira é a violência estrutural econômica (produção de mercadorias) e a segunda consiste na violência estrutural financeira (distribuição dos bens da sociedade e sua desigualdade).

Para E. B. Pachukanis, o direito penal deve ser considerado como um elemento integrante da superestrutura do Estado Capitalista. Desse modo, aquele está subordinado a uma forma básica de interação nesta sociedade: a relação de troca equivalente. $O$ direito penal não se limita, contudo, às relações jurídicas abstratamente consideradas, mas, sim, integra o macrossistema que engloba a jurisdição penal como encarnação da luta de classes. Afirma o autor que "quanto mais aguda e encarniçada se torna esta luta, tanto mais a dominação de classe encontra dificuldades em se efetivar no interior da forma jurídica". Prossegue o autor, afirmando que nestes casos a justiça penal imparcial, “com as suas garantias jurídicas, é rechaçada, e toma frente uma organização direta da violência de classe, cujas ações são conduzidas unicamente por considerações de oportunidade política" (PACHUKANIS, 1988, p. 126). 


\section{A VIOLÊNCIA ESTRUTURAL ECONÔMICO-FINANCEIRA NO ÂMBITO RURAL}

A violência estrutural econômico-financeira no âmbito rural é caracterizada pela aplicação privilegiada da lei para determinados segmentos da sociedade. Exemplo disso é a doação de terras públicas a grandes instituições financeiras na época do regime militar, mais especificamente ao Banco Bradesco S.A. e ao Banco Real S.A. (atual Banco Santander S.A.), entre outras (FERNANDES, 1999, p. 191). José de Souza Martins frisa que, "a partir do golpe de Estado de 1964 e do estabelecimento da ditadura militar, a Amazônia transformou-se num imenso cenário de ocupação territorial massiva, violenta e rápida, processo que continuou, ainda que atenuado, com a reinstauração do regime político civil e democrático em 1985" (MARTINS, 1996, p. 26).

Durante o período do regime militar, os povos tradicionais localizados na Amazônia sofreram diversos ataques organizados; calcula-se, segundo José da Silva Martins, que 92 (noventa e dois) atos de agressões coletivas foram orquestrados, sendo a maioria por grandes proprietários de terras e milícias privadas, sempre com o uso de arma de fogo. De outro lado, diversas tribos atacaram, de 1968 a 1990, grandes fazendeiros, com armas consideradas primitivas e inofensivas, como borbunas e arco-e-flecha. Isso é muito parecido com os massacres policialescos, onde se apreendem diversas armas de fogo, com alta capacidade de letalidade e, de outro lado, armas brancas, que mais são consideradas instrumentos de lavoura. O desnivelamento entre vencidos e vencedores - em termos de letalidade - sempre é claro. Assim, a competição entre diversos setores ligados ao capital faz da violência um importante mecanismo nesse espaço; o espaço da concentração da propriedade agrária também é o espaço de concentração de conflitos auxiliados pela violência estrutural reproduzida ao campo institucional.

As expulsões institucionalizadas permanecem. As ordens judiciais de reintegração de posse e despejos judiciais contra pequenos agricultores posseiros de terras devolutas e sem uso (minifundistas), com o intuito de privilegiar multinacionais e grandes latifundiários ${ }^{2}$, continuam sendo uma prática comum na rotina judiciária. Esta violência institucional promovida pela justiça hegemônica - demonstra que a violência estrutural é reproduzida. A Comissão Pastoral da Terra, em 2006, registrou 1.212 ocorrências desse tipo de violência 
(despejos judiciais). Destas ocorrências, 19.449 famílias foram despejadas, 1.809 expulsas compulsoriamente com a conivência do Poder Judiciário e 12.494 ameaçadas de efetiva expulsão. As ameaças de despejo não ficaram para trás; foram relatadas nesse mesmo ano 16.389 ameaças de despejo, que geraram 5.222 casas destruídas ou queimadas e, com elas, roças e bens. Também como exemplo:

Um soldado da P2 me levou por trás da casa sede da fazenda enquanto traziam o Lorival, sem que eu pudesse vê-lo, pois ele já estava torturado, então me levaram até a mangueira do gado. Lá tinha grandes tanques de cimento que serviam de bebedouros, fizeram-me ajoelhar para que eu falasse que eram as lideranças que organizavam o MST na região e onde estava o Fusca prata (um veículo usado pelo MST). Quando eu disse que era bóiafria, tinha chegado recentemente na fazenda, não sabia de nada, começaram a me torturar, foram duas horas e meia de tortura, das $11 \mathrm{~h}$ até as $13 \mathrm{~h} 30 \mathrm{da}$ tarde. Me torturaram algemado aonde meus braços estão cheios de feridas das algemas. Na tortura teve afogamento, enforcamento, espancamento com pisoteiro na barriga, tiraram minha roupa e ameaçaram estuprar-me com uma cana-de-açúcar, depois mandaram eu correr para que eles pudessem me matar, onde eu não corri. Colocaram-me de joelho em frente um monte de esterco de vaca recém-estercado, encostaram uma faca em meu pescoço e me fizeram comer mais ou menos meio quilo de esterco. Foi bárbaro e humilhante. Depois me levaram até a viatura onde já estavam os outros presos. Foram três os torturados. Eu o Lorival e o Aristides, que nos torturou foi o Grupo de Operações Especiais (GOE) e a P2 (polícia secreta da Polícia Militar), onde confirmaram que foram eles que mataram um sem-terra em Querência, recentemente, e recebiam muito bem da UDR (União Democrática Ruralista) para fazer isto, também disseram que estavam perdendo dinheiro, pois não tinham conseguido nada (BORDIGNON, 1999, p. 12).

\footnotetext{
2 Sobre a venda de terras para grupos estrangeiros, cite-se o artigo elaborado por Ariovaldo Umbelino de Oliveira: "O Sr. João Inácio diz ter adquirido em Altamira 1.015.860 hectares, em São Félix 3.602.072 hectares, em Vizeu 390.040 hectares, em Paragominas 191.164 hectares, e em Conceição do Araguaia outros 257.004 hectares. Ainda nesse estado em Paragominas, John Davies afirma ter comprado 52.272 hectares; em Almerim, o grupo National Bulk Carriers adquiriu 1.250.000 hectares; em Tomé-Açu, a Jamic comprou 25.800 hectares; em Portel e Melgaço a Georgia Pacific tem 400.000 hectares; em Melgaço, Robert Richard Morrow possui 40.658 hectares; em Portel, Curralinho, Breves, Anapu, Anajás, e em Bagre, Robin Hollie Mac Glow teria adquirido 400.000 hectares; em Açará, Jacob Klauss tem área ignorada; em Itaituba, Arruda Pinto diz ter 300.000 hectares; em Curralinho, Gork Stinson tem 8.344 hectares, Ed Kay Properties tem 1.659 hectares e Missio Bay outros 632 hectares; e em Portel, Hartzel Vinhard tem 576 hectares. Deixa de ser incluída a relação de propriedades negociadas pelo grupo Nadyr Helou que no momento são objeto de investigações. Também é conveniente ressaltar que a maioria das terras em poder do grupo João Inácio, que perfazem um total de mais de 5.000.000 hectares, muitas delas foram adquiridas por requisição ao Estado, como terras devolutas, o que fere frontalmente o disposto na Constituição do Brasil". (OLIVEIRA, Ariovaldo Umbelino. A Questão da Aquisição de Terras por Estrangeiros no Brasil - um retorno aos dossiês. Agrária, São Paulo, v. 12, p. 3-113, 2011).
} 
Outro exemplo é o de outubro de 2007, ocorrido no Estado do Rio Grande do Sul, na cidade de São Gabriel, em que grandes produtores rurais elaboraram um manifesto, com evidente conteúdo criminalizante em face do Movimento dos Trabalhadores Rurais Sem Terra. Cite-se a passagem do manifesto constante na obra Da Miséria Ideológica à Crise do Capital:

\begin{abstract}
Nós, produtores e produtoras do Estado do RS, reunidos em São Gabriel, calcados na inabalável crença na Democracia e no Estado de Direito como base intransponível para crescimento sustentado da Nação, na ocasião em que nos reunimos para receber em nossa terra a presença de Sua Excelência o Ouvidor de Segurança Pública do RS, Adão Paiani, vimos através deste Manifesto, expressar de maneira clara e veemente, nossa indignação frente à forma canhestra, dúbia e beligerante com que os entes do Estado conduzem a Política Nacional de Reforma Agrária no Estado do Rio Grande do Sul.

$[\ldots]$

Se tu, gabrielense amigo, fores procurado por um faminto do MST dê-lhe um prato de comida com três colheres cheias de qualquer veneno para rato. Se possui um avião agrícola, pulveriza à noite 100 litros de gasolina em voo rasante sobre o acampamento de lona dos ratos. Sempre terá uma vela acesa para terminar o serviço e liquidar com todos eles. Se és proprietário de terras ao lado do acampamento, usa qualquer remédio de banhar gado na água que eles utilizam para beber. Rato envenenado bebe mais água ainda. Se possui uma arma de caça calibre 22, atire de dentro do carro contra o acampamento, o mais longe possível. A bala atinge o alvo mesmo a 1200 metros de distância (PINASSI, 2009, pp. 83-84).
\end{abstract}

Vale ressaltar que esses ruralistas que protestaram contra o Movimento dos Trabalhadores Rurais Sem Terra são sócios da Aracruz Celulose, Votorantim e Stora Enso, cujas propriedades rurais somam 150 mil hectares de terra com a finalidade de plantio de eucalipto e pinus para a produção de celulose. A meta do ano de 2016 é alcançar um milhão de hectares, equivalente ao território do Líbano.

Os argumentos da antidemocracia e antisoberania dos movimentos sociais são proclamados pelas agências do Estado, em evidente proteção às classes dominantes. No entanto, nada mais antidemocrático do que a polarização de riqueza. Como exemplo desta visão autoritária, a Polícia Militar revistou diversas crianças que estavam na entrada da cidade de São Gabriel - RS, provenientes de acampamentos do MST, em evidente conduta estigmatizante. 
Em contrapartida, a criminalidade política deve ser vista como crimes praticados pelo Estado, assim como pelas elites econômicas que produzem cadáveres e edificam a política criminal de derramamento de sangue.

Entre as formas de violência mais presentes nas instituições do Estado, estão os delitos que não oferecem diretamente lesão às vítimas. Porém, sistematicamente, sua produção/reprodução gera danos incalculáveis para a sociedade.

A corrupção, por exemplo, é a busca incessante de mais poder e autoridade, assim como recursos econômicos mediados pela conduta criminosa.

O sistema político capitalista seria, nas democracias de massas, quase um sinônimo de corrupção. Isso se dá, segundo Vicenzo Ruggiero, porque “a burocracia, que ideologicamente pretende a regularidade no exercício profissional, pode tornar-se independente de sua função original” (2005, p. 136). Essa independência acaba gerando a confusão entre o público e o privado, reproduzindo os interesses das classes dominantes.

No caso da violência no campo, inúmeros são exemplos visíveis de repressão que ocorrem na terra brasilis: legitimação de terras em registros públicos em troca de dinheiro; julgamentos parciais em favor de latifundiários e grileiros de terras; e impunidade judiciária aos assassinatos de ativistas de direitos humanos e lideranças sindicais ou de movimentos sociais de luta pela reforma agrária.

Um exemplo corroborado por Vicenzo Ruggiero, sobre a coadunação entre classes dominantes e a corrupção política na Inglaterra, merece ser transcrito:

Esta interrelação das esferas públicas e privadas, alguma vez tida como inevitável, é parte do desenvolvimento conatural das elites inglesas, as quais crescem e são alimentadas e "fabricadas" dentro de redes de afiliação inacessíveis à maioria. Em tais redes, o intercâmbio corrupto pode não ser percebido como tal, posto que tem lugar em espaços "invisíveis" que estão tão distantes da sociedade civil como as elites que o promovem. As elites, que chegaram a envolver-se em práticas corruptas, podem sentir tranquilamente que esse passar por cima de algumas regras é uma falta quando se pesa contra sua importante missão, que seria a reprodução dos papéis e hierarquias que, durante séculos, garantiram o poder internacional, a estabilidade doméstica e uma boa dose de difundida admiração a que se atribuiu o nome de "anglofilia". (2005, p. 175).

Apesar de, no Brasil, não existirem títulos honoríficos como na cultura britânica, existem certos privilégios que são distribuídos de modo desigual entre classe criminalizante e 
classe criminalizada. Um exemplo é parte da Amazônia que foi doada no período do regime militar a duas instituições financeiras privadas: Banco Bradesco S.A. e Banco Real S.A (atual Santander).

A violência política do Estado também se capilariza na própria construção da lei penal (criminalização). Se buscarmos a definição de crime, encontraremos algo parecido com uma categoria de atos puníveis. No entanto, a questão-chave que Willen Bonger - um dos precursores do estudo das relações econômicas com a criminalidade - traz em sua obra Criminalidade e Condições Econômicas, é que a problemática não é o que é crime, mas sim, de quem são, através da pergunta Os atos puníveis são de quem? A resposta residiria na percepção de que não se constrói a criminalização para um indivíduo ou grupo de indivíduos, mas, sim, para um setor social. Logo, a punição, em um sentido impróprio da palavra, teria a conotação de vingança de um grupo social em face de outro (1969, p. 21).

O crime, assim - violência política direcionada abstratamente e pretensamente a um grupo de pessoas -, seria, segundo Willen Bonger, um ato antissocial, um ato que representa um considerável degrau de interesses de certo grupo de pessoas, em que o Rule Penal Law na verdade é uma Class Rule Penal Law (1969, p. 23).

Assim, o poder punitivo do estado é o poder organizado criminalizador da classe dominante. Quando esta se mantém no poder por muito tempo, seus interesses se tornam normas jurídicas aceitas pelos restantes integrantes do Estado.

A justiça, em especial a penal, é uma organização que reproduz a violência estrutural no âmbito institucional. Isso se dá como uma forma evidente de luta de classes. A justiça penal reflete os anseios econômico-financeiros e políticos da classe dominante, considerando, inclusive, atrocidades como algo banal, cujos verdadeiros responsáveis nunca são responsabilizados. Juarez Cirino dos Santos expõe sobre a lógica da violência estrutural no âmbito do campesinato:

A violência estrutural sobre esses segmentos de trabalhadores agrícolas assume, simultaneamente, formas econômicas e financeiras, quer pela impossibilidade de resistirem ao avanço do capitalismo no campo, formando grandes latifúndios, quer pela necessidade de assalariamento temporário para complementarem seus rendimentos, quer pela ausência absoluta ou dificuldades extremas de acesso ao crédito rural, desviado para os grandes 
empreendimentos agrícolas promovidos pelo capital bancário e industrial e pelos latifundiários, os beneficiários naturais e exclusivos da política creditícia no campo. (SANTOS, 1984, p. 89).

Mas o que vem a ser luta de classes e qual a sua relação com o direito e o direito penal? Um autor socialista soviético chamado Petr Ivanovich Stucka afirma que o direito incluído o direito penal- é correspondente ao interesse da classe dominante. Interesse é a busca do que é "útil ou vantajoso para um indivíduo ou grupo de indivíduos, em contraposição com o vantajoso ou útil para outros indivíduos" (STUCKA, p. 40). A lei penal é algo que é útil ou vantajoso para a classe hegemônica.

Classe, por sua vez é conceituada como um grupo de pessoas cuja diferença em relação às outras se dá pelo status que ocupa na cadeia de produção social historicamente determinada. Completando essa assertiva, Vladmir I. Lênin coloca que "as classes são grupos humanos, sendo que um deles pode apropriar-se do trabalho do outro em razão dos diferentes lugares que um e outro ocupam num determinado regime de economia social" (1985, p. 485). A sociedade de classes surge quando o sistema de produção é monopolizado por um segmento da sociedade (criminalizadores) em detrimento de outro segmento (criminalizados).

Trata-se de uma relação de dominação e sujeição que é reproduzida no sistema judiciário, principalmente porque o "crime é a manifestação da condição material da sociedade", ou seja, "a manifestação da condição material do sistema capitalista" (QUINNEY, 1977, p. 34-35). Essa dominação e sujeição se expressam no poder organizado do Estado e em suas instituições como instrumento de coerção e de persuasão, nos mesmos termos que o jus civile romano ${ }^{3}$.

\footnotetext{
${ }^{3}$ Sobre esta equiparação: "Originalmente, o direito da classe dominante, o jus civile, referia-se a um reduzido círculo de pessoas: tratava-se mais de privilégio do que direito. [...] A estas alturas, o poder já possuía, como em qualquer Estado, uma dupla função: era um instrumento de coerção e um instrumento de persuasão. O mecanismo de coerção era constituído pelo poder militar, enquanto que os órgãos de persuasão foram primeiramente a casta sacerdotal e depois a casta dos juristas e os diversos tipos de tribunais populares e, por último, como em qualquer época de decadência da classe dominante, outra vez a Igreja, que agia, simultaneamente, como autoridade e como propagandista. Neste tipo de Estado, todas as instituições, tanto as militares do Estado como as sociais e eclesiásticas, têm a mesma estrutura, adaptada à forma primitiva da exploração feita mediante o cativeiro e o imposto". (STUCKA, Petr Ivanovich, op. cit., p. 61).
} 


\section{CONCLUSÃO}

A justiça como um todo, e especialmente a justiça penal, é classista. Confunde os interesses de bem comum com interesses das classes dominantes.

O objeto principal desse tipo de crítica é a análise da relação entre violência econômica (estrutural-capitalista) e violência institucional (Aparelhos Repressivos do Estado), são as criminalizações secundárias oficiais, promovidas pelo sistema penal formal.

No entanto, a proposta feita no trabalho é demonstrar a violência estrutural agrária e como há uma lógica na marcha fúnebre da violência institucional da Justiça Criminal. Este tipo de atuação estatal, nada mais é que um sistema de contenção (controle social) da violência contra-hegemônica, ou seja, da busca pelos direitos através de movimentos sociais.

O fluxo histórico dos conflitos agrários permite a visualização da tradição do conflito de classes e as suas estratégias de poder (subterrâneo). A relação entre a polarização do capital e o uso de violência institucional e estrutural possibilita um campo fértil para que o direito penal subterrâneo se desenvolva, assim como a atuação violenta do Estado Capitalista.

\section{REFERÊNCIAS BIBLIOGRÁFICAS}

ALTHUSSER, Louis. Aparelhos ideológicos de Estado. Trad. Walter José Evangelista e Maria Laura Viveiros de Castro. Rio de Janeiro: Edições Graal, 1985.

BATISTA, Nilo. Entrevista: Todo Crime é Político. Revista Caros Amigos, São Paulo, Ano VII, número 77, ago. 2003.

BENJAMIN, Walter. Obras escolhidas 1: magia e técnica, arte e política. 10. ed. Brasília: Brasiliense, 1996.

BONGER, Willen. Criminality and economic conditions. Londres: Indiana University Press, 1969. 
BORDIGNON, Valdecir. Carta da Prisão. Caros Amigos, São Paulo, n. 27, p 18-9, jun. 1999.

CANDIDO, Antonio. Os parceiros do Rio Bonito. Estudo sobre o caipira paulista e a transformação dos seus meios de vida. Rio de Janeiro: José Olympio, 1964.

CARDOSO, Franciele Silva. A luta e a lida: Estudo do controle social do MST nos acampamentos e assentamentos de reforma agrária. São Paulo: IBCCRIM, 2013.

CHAPMAN, Dennis. Sociology and the stereotype of the criminal. Londres: Tavistock, 1968.

CHRISTIE, Nils. Uma razoável quantidade de crime. Trad. André Nascimento. Col. Pensamento Criminológico Vol. 17. Rio de Janeiro: Revan/ICC, 2011.

DOMINGOS NETO, Manuel. O Novo Mundo Rural. In: MARTINS, Mônica Dias (org). $O$ Banco Mundial e a Terra: ofensiva e resistência na América Latina, África e Ásia. São Paulo: Viramundo, 2004.

GIRARDI, Eduardo Paulon. Proposição teórico-metodológica de uma Cartografia Geográfica Crítica e sua aplicação no desenvolvimento do Atlas da Questão Agrária Brasileira. 2008. Tese (Doutorado em Geografia) - Faculdade de Ciências e Tecnologia, Universidade Estadual Paulista, Presidente Prudente, 2008.

LÊNIN, Vladmir I. Obras escolhidas. Vol. V. Buenos Aires: Ed. Cartago, 1985.

MARTINS, José de Souza. O tempo da fronteira: Retorno à controvérsia sobre o tempo histórico da frente de expansão e da frente pioneira. Tempo social, v. 8, n. 1, maio de 1996.

MATTEI, Ugo; NADER, Laura. Pilhagem: Quando o Estado de Direito é Ilegal. Trad. Jefferson Luiz Camargo. São Paulo: WMF Martins Fontes, 2013.

MENEGAT, Marildo. Estudos sobre ruínas. Rio de Janeiro: Revan/ICC, 2012.

OLIVEIRA, Ariovaldo Umbelino. A Questão da Aquisição de Terras por Estrangeiros no Brasil - um retorno aos dossiês. Agrária, São Paulo, v. 12, p. 3-113, 2011.

PACHUKANIS, E. B. Teoria geral do direito e marxismo. Trad. Silvio Donizete Chagas. São Paulo: Editora Acadêmica, 1988. 
PEREIRA DE ANDRADE, Vera Regina (org.). Verso e reverso do Controle Penal: (Des)Aprisionando a Sociedade da Cultura Punitiva. Volume 2. Florianópolis: Boiteaux, 2003.

PINASSI, Maria Orlanda. Da miséria ideológica à crise do capital: uma reconciliação histórica. São Paulo: Boitempo, 2009.

QUINNEY, Richard. Class, State and Crime: on the theory and pratice of criminal justice. Nova Iorque: David MacKay Company, 1977.

RUGGIERO, Vicenzo. La violencia política: Um análisis criminológico. Trad. Miguel A. Pastor Pérez. México: Antrophos, Universidad Autônoma Metropolitana - Azcapotzalco; Barcelona: Observatori del Sistema Penal i els Drets Humans de la Universitat de Barcelona, 2009.

RUSCHE, Georg; KIRCHHEIMER, Otto. Punição e estrutura social. Trad. Gizlene Neder. 2. Ed. Rio de Janeiro: Revan/ICC, 2004.

SANTOS, Juarez Cirino. As Raízes do Crime: Um Estudo sobre as Estruturas e as Instituições da Violência. Rio de Janeiro: Forense, 1984.

SOUSA SANTOS, Boaventura. Para uma revolução democrática da justiça. 3. Ed. São Paulo: Cortez, 2011. Renovar a teoria critica e reinventar a emancipação social. Trad. Mouzar Benedito. São Paulo: Boitempo, 2007. 